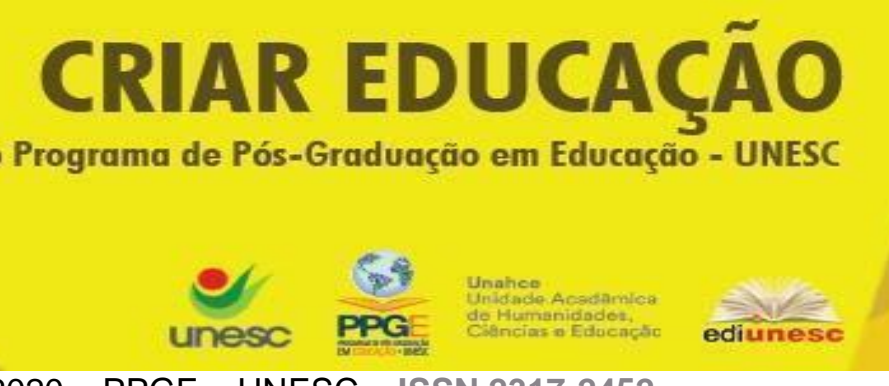

Criar Educação, Criciúma, v. 9, no2, Edição Especial 2020.- PPGE - UNESC - ISSN 2317-2452

\title{
REFLEXÕES INTERDISCIPLINARES SOBRE A PANDEMIA DA COVID-19: UM RELATO DE EXPERIÊNCIA DO CICLO DE PALESTRAS ONLINE
}

\begin{abstract}
Roselaine Ripa ${ }^{1}$
Resumo: Tem-se com este trabalho o objetivo de apresentar o relato de experiência sobre o Ciclo de Palestras: reflexões interdisciplinares sobre a pandemia, que aconteceu online, entre março e junho de 2020, promovido pelo Grupo de Pesquisa Nexos: Teoria Crítica e Pesquisa Interdisciplinar - Sul, com o propósito de promover debates com professores(as) do Centro de Educação a Distância (CEAD), da Universidade do Estado de Santa Catarina (UDESC), sobre as transformações sociais provocadas pela pandemia da Covid-19 e suas relações com temáticas da educação. Para avaliar o impacto e as contribuições em termos de formação crítica na perspectiva da Teoria Crítica da Sociedade, foram utilizados dados registrados no questionário de avaliação da atividade proposta aos(às) acadêmicos(as) dos cursos de graduação do CEAD/UDESC que participaram dessas palestras online.
\end{abstract}

Palavras-chave: Pandemia. Educação a distância. Relato de experiência.

\section{INTERDISCIPLINARY REFLECTIONS ON PANDEMIC: AN EXPERIENCE REPORT OF THE ONLINE LECTURE CYCLE}

\begin{abstract}
This work aims to present the experience report on the Lecture Cycle: interdisciplinary reflections on the pandemic, which took place online, between March and June 2020, promoted by the Nexos Research Group: Critical Theory and Interdisciplinary Research - Sul, with the purpose of promoting debates with teachers from the Centro de Educação a Distância (CEAD), from the Universidade do Estado de Santa Catarina (UDESC), about the social transformations caused by the Covid-19 pandemic and its relations with themes of education. To assess the impact and contributions in terms of critical training in the perspective of the Critical Theory of Society, data recorded in the questionnaire for the evaluation of the activity proposed to the academics of the undergraduate courses of CEAD/UDESC who participated in these studies were used. online lectures.
\end{abstract}

Keywords: Pandemic. Distance education. Experience report.

\section{Introdução}

Para iniciar a reflexão sobre este momento de pandemia da Covid-19, recorrese à pintura surrealista do espanhol Salvador Dalí, intitulada Geopoliticus Criança

\footnotetext{
${ }^{1}$ Doutora em Educação (UFSCar). Professora Efetiva na Universidade do Estado de Santa Catarina (UDESC). Endereço postal: Servidão Catavento, 91, apto 106. Campeche. Florianópolis/SC. E-mail: roselaine.ripa@udesc.br
} 
assistindo ao nascimento do novo homem (THE DALI, 2017), que data de 1943 e encontra-se no Museu Salvador Dalí, em São Petersburgo, Flórida, EUA. Apesar do otimismo diante dos anseios do nascer de um novo mundo e de um novo ser humano após a Segunda Guerra Mundial, a atmosfera retratada pelo artista é de ameaça e tristeza. Na pintura, observa-se uma criança que assiste, assustada, ao nascimento desse novo ser, ao lado de uma mulher, que aponta para o homem tentando sair de um ovo, com casca mole, onde os continentes estão representados de forma diluída. Da América do Sul, sai uma lágrima e, da abertura na casca, escorre uma gota de sangue.

Assim como a criança retratada por Salvador Dalí, a população mundial tem assistido assustada às consequências da pandemia causada pelo novo coronovírus. Alguns estão ainda otimistas quanto ao nascimento de um novo mundo e ser humano após os impactos econômicos, sociais e emocionais que uma situação pandêmica impõe, considerando que tantos casos e mortes em âmbito mundial seriam capazes de provocar o surgimento de um mundo mais solidário e humanizado, com uma relação mais equilibrada com a natureza, já que a Covid-19 atingiu a todos sem distinção. Porém, são as ações de proteção aos indivíduos que estão imperando durante a pandemia, nem ações de ajuda entre as nações. Considerando-se o contexto brasileiro, ficam ainda mais evidentes as imposições deste capitalismo perverso que continua determinando as decisões dos poderes públicos, acentuando as diferenças e as desigualdades já existentes. Infelizmente, nada indica que haverá seres melhores e mais humanizados de um dia para o outro. Afinal, se durante a pandemia os direitos sociais têm sido diluídos, as instituições democráticas têm sido atacadas e os discursos de ódio, o negacionismo e as ações que se aproximam de práticas fascistas têm sido ampliados, o contexto de tristeza e ameaça tende a permanecer.

Do Brasil continua a sair uma lágrima, mantendo a atualidade da obra retratada por Salvador Dalí, com as devidas diferenças do contexto histórico.

Diante desse cenário, que tem consequências desastrosas no âmbito da educação, o Grupo de Pesquisa Nexos: Teoria Crítica e Pesquisa Interdisciplinar - 


\section{Sul (CNPQ/UDESC) $)^{2}$ propôs o Ciclo de Palestras online: reflexões}

interdisciplinares sobre a pandemia. Seu objetivo foi promover debates com professores(as) de diversas disciplinas do Centro de Educação a Distância (CEAD), da Universidade do Estado do Santa Catarina (UDESC), sobre as transformações sociais provocadas pela pandemia da Covid-19 e suas relações com as temáticas da área da educação.

Essa ação tornou-se uma tentativa de (1) acolher a comunidade acadêmica, (2) provocar (auto)reflexões críticas na perspectiva da Teoria Crítica da Sociedade, (3) contribuir para preservar e defender a liberdade humana, e (4) livrar a todos(as) do aprisionamento de um eclipse da razão, com a "[...] ideia de que hoje importa mais conservar a liberdade, ampliá-la e desdobrá-la, em vez de acelerar, ainda que indiretamente, a marcha em direção ao mundo administrado" (ADORNO; HORKHEIMER, 1985, p. 10).

Pesquisadores(as) e educadores(as) não poderiam ignorar as consequências de um contexto de pandemia no Brasil e os seus desdobramentos no âmbito educacional. Era preciso trazer à tona discussões sobre o papel da ciência, o cuidado com os deficientes, a sexualidade, a sustentabilidade, a educação a distância, a implantação do ensino remoto, a inclusão e a exclusão digital, e a mediação docente online.

Dessa forma, este trabalho apresenta o relato de experiência sobre o Ciclo de Palestras online: reflexões interdisciplinares sobre a pandemia, analisando os resultados dessa atividade online que mobilizou ações de ensino, pesquisa e extensão, bem como suas contribuições para a formação dos(as) acadêmicos(as). Para isso, foram utilizadas as avaliações finais enviadas por 74 participantes que estavam matriculados(as) nos cursos de graduação do CEAD/UDESC.

A seguir, contextualiza-se o ciclo de palestras online e sua contribuição para a (auto)reflexão crítica na perspectiva da Teoria Crítica da Sociedade.

\footnotetext{
${ }^{2}$ Mais informações disponíveis em: <http://dgp.cnpq.br/dgp/espelhogrupo/6508234166905667>. Acesso em: 28 jun. 2020.
} 


\section{0 ciclo de palestras online: objetivos e temáticas}

O ciclo de palestras online começou no dia 15 de abril de 2020, tendo como público-alvo acadêmicos(as) do CEAD/UDESC, servidores(as) técnicos(as) e docentes da UDESC, bem como a comunidade interessada. Inicialmente, sua duração foi prevista para quatro semanas, mas, devido ao grande número de acessos e pedidos de continuidade vindos dos participantes, ampliou-se para oito semanas, com término em 3 de junho de 2020.

Sempre às quartas-feiras, com início às 16 horas, o número de ingressantes na plataforma da $\mathrm{RNP}^{3}$ atingia, com antecedência, o limite das 75 vagas do ambiente virtual. Por isso, também foi disponibilizado semanalmente um link para que os(as) demais interessados(as) pudessem acessar via streaming e acompanhar as transmissões ao vivo. A média de participação online, em cada palestra, foi de 270 pessoas, com uma quantidade surpreendente de interações realizadas via bate-papo público e registros de perguntas e comentários para os(as) professores(as) palestrantes.

Para ampliar o acesso, providenciou-se a interpretação em Libras ao vivo e a socialização das gravações para quem não tivesse disponibilidade de horário para acompanhar de forma síncrona. Com os registros das avaliações, pôde-se aperfeiçoar a parte técnica da transmissão, com disponibilização de materiais no recurso de notas compartilhadas, orientações de acesso à plataforma e divulgação mais eficaz dos links.

Com tantas lives sendo propostas desde março de 2020, não se tinha intenção de compor mais um projeto de entretenimento. Por isso, optou-se por uma plataforma institucional e certificação apenas dos(as) acadêmicos(as) do CEAD, que tinham acesso ao ambiente virtual de aprendizagem (AVA - Moodle) e podiam preencher uma avaliação para garantir a emissão da frequência, o que ajudou na somatória dos créditos de atividades complementares, que são obrigatórios (UDESC, 2012).

\footnotetext{
${ }^{3}$ Comunidade disponível em: <https://conferenciaweb.rnp.br/spaces/ciclo-de-palestras>.
} 


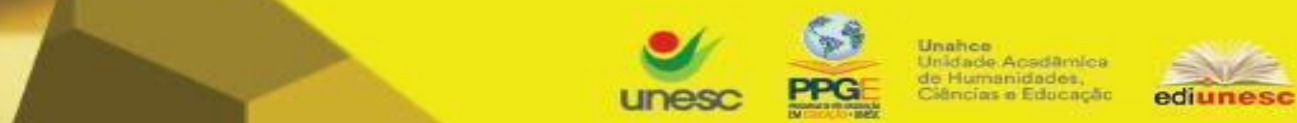

Criar Educação, Criciúma, v. 9, no2, Edição Especial 2020.- PPGE - UNESC - ISSN 2317-2452

Sendo assim, com todas as demandas e dificuldades provocadas pelo contexto da pandemia, foi necessário abrir um espaço de interação, acolhimento e diálogo, principalmente para a comunidade acadêmica do CEAD/UDESC. Por isso, o convite não foi amplicado para professores(as) pesquisadores(as) externos(as) serem palestrantes, para fortalecer os laços com os(as) docentes do CEAD/UDESC em um semestre que teve seu início interrompido logo após a finalização do período de matrícula. A preocupação era ainda maior em atender às demandas das primeiras fases, pois, dos 339 acadêmicos(as) ativos no CEAD em 2020-1, 160 eram provenientes do último vestibular da UDESC. Os(as) professores(as) do CEAD/UDESC aceitaram prontamente o convite, fazendo as transmissões de suas casas, que passaram a compor o cenário do ciclo de palestras online.

Além disso, a discussão sobre o retorno ou não das atividades de ensino para cumprir os fluxos institucionais e atender a uma matriz curricular consolidada não poderia impedir a discussão de temáticas que se faziam urgentes e necessárias no contexto da pandemia. Por isso, os temas foram organizados conforme o quadro a seguir.

\begin{tabular}{|c|c|c|}
\hline Data & Tema & Palestrante \\
\hline $15 / 04 / 2020$ & $\begin{array}{l}\text { As ciências da educação e suas reflexões no contexto } \\
\text { da Pandemia }\end{array}$ & Lidnei Ventura \\
\hline $22 / 04 / 2020$ & $\begin{array}{l}\text { A experiência da deficiência em tempos da Pandemia, } \\
\text { acessibilidade e ética do cuidado }\end{array}$ & Geisa Letícia Bock \\
\hline $29 / 04 / 2020$ & $\begin{array}{l}\text { Algumas reflexões sobre sexualidade em tempos de } \\
\text { isolamento social }\end{array}$ & $\begin{array}{l}\text { Gabriela Maria Dutra de } \\
\text { Carvalho }\end{array}$ \\
\hline $06 / 05 / 2020$ & $\begin{array}{c}\text { Tecnologia em tempos de pandemia - a EAD enquanto } \\
\text { panacéia tecnológica na Educação Básica }\end{array}$ & Vitor Malaggi \\
\hline $13 / 05 / 2020$ & $\begin{array}{l}\text { Educomunicação e sustentabilidade: saúde psicossocial } \\
\text { em contexto de pandemia de desinformação }\end{array}$ & Rafael Gué Martini \\
\hline $20 / 05 / 2020$ & $\begin{array}{l}\text { Acessibilidade e Pandemia: a Interdisciplinaridade } \\
\text { Necessária para Acolhimento das Diferenças }\end{array}$ & $\begin{array}{c}\text { Rose Clér Estivalete } \\
\text { Beche e Débora } \\
\text { Marques Gomes }\end{array}$ \\
\hline $27 / 05 / 2020$ & $\begin{array}{l}\text { Inclusão e exclusão digital em contextos de pandemia: } \\
\text { que educação estamos praticando e para quem? }\end{array}$ & Karina Marcon \\
\hline 03/06/2020 & $\begin{array}{l}\text { Mediação pedagógica online e educação mediada por } \\
\text { tecnologias digitais em tempos de Pandemia }\end{array}$ & Lidiane Goedert \\
\hline
\end{tabular}


A escolha foi iniciar o ciclo de palestras online com as contribuições das ciências da educação para o debate sobre os dilemas ontológicos, éticos e estéticos que estavam sendo impostos à sociedade, em âmbito internacional, devido à pandemia provocada pelo novo coronavírus. Com uma perspectiva multidisciplinar, as discussões das diversas áreas foram utilizadas para provocar o debate sobre a condição fundamental do ser-aí/ Dasein no mundo: a preservação da vida humana.

Outro tema, abordado em duas palestras, foi a questão da acessibilidade e ética do cuidado em tempos de pandemia, o que tem sido pouco discutido e divulgado pelas instituições educacionais, por exemplo. Em uma delas, o objetivo foi trazer para discussão as transformações e implicações do isolamento para as pessoas com deficiência, destacando a importância de se efetivarem ações de inclusão, tais como as políticas públicas do cuidado e acessibilidade. A outra teve como foco a reflexão sobre as transformações impostas pela pandemia aos(às) estudantes com deficiência, transtornos e necessidades educacionais específicas, bem como a necessidade de acolhimento de suas necessidades individuais e o papel dos(as) professores(as) no trato com essas questões.

Nessa mesma linha do cuidado, uma das palestras abordou a sexualidade enquanto dimensão humana, trazendo reflexões sobre como as questões relacionadas aos afetos nos diferentes relacionamentos, incluindo comportamentos sexuais infantis, podem envolver dúvidas e curiosidades no contexto de isolamento social.

No campo da educomunicação, outra palestra procurou tecer discussões envolvendo a sustentabilidade e a difusão de desinformação no contexto da pandemia. O objetivo foi provocar reflexões sobre como se proteger dessa realidade e, ao mesmo tempo, atuar de forma propositiva para melhorar a saúde psicossocial e a realidade de colapso socioambiental.

O tema da educação a distância e seus desdobramentos no contexto da pandemia foi abordado em três palestras. Considerando que o CEAD/UDESC tem uma longa trajetória na oferta de cursos nessa modalidade, com ações de extensão e 
pesquisa consolidadas, essa temática pretendia responder as dúvidas das comunidades interna e externa, a partir das ações para a implantação, muitas vezes de forma improvisada, das denominadas atividades pedagógicas não presenciais nas diversas redes de ensino, aprovadas pelo Parecer CNE n 5/2020 (BRASIL, 2020). A primeira palestra teve como objetivo discutir em que medida a adoção da educação a distância (EAD) na educação básica estava constituindo um rebaixamento da formação humana integral enquanto projeto político-pedagógico, bem como da própria EAD enquanto modalidade educativa, que estava sendo reduzida a um conjunto de relações instrumentais tecnologicamente mediatizadas. Na sequência, outra palestra trouxe discussões sobre inclusão e exclusão digital, destacando que, para além do acesso, era necessária a apropriação social das tecnologias, de forma crítica, autoral e criativa, implicando não somente a instrumentalização e a fluência tecnológica. Para finalizar, a última palestra provocou discussões sobre as especificidades do processo de mediação pedagógica, quando o contexto de ensino e aprendizagem é online ou mediado por tecnologias digitais, como um aspecto fundamental para embasar as propostas de reposição/continuidade dos estudos no contexto da pandemia.

Das 270 pessoas que, em média, participaram de cada dia da palestra, nem todas eram acadêmicos(as) do CEAD, conforme já mencionado. Considerando-se os que solicitaram certificação, destaca-se que 50\% dos(as) participantes(as) tinham vínculo com a graduação. Desses, 74 responderam a avaliação final referente ao ciclo de palestras online e autorizaram o uso dos dados, que serão apresentados a seguir.

\section{Ciclo de palestras online: as avaliações dos(as) acadêmicos(as)}

O CEAD/UDESC tem 339 alunos(as) matriculados(as) em 2020-1 e oferece, atualmente, quatro cursos de graduação na modalidade a distância: Pedagogia, Licenciatura em Informática, Licenciatura em Ciências Biológicas e BICT Bacharelado Interdisciplinar em Ciência e Tecnologia (ênfase 1: metodologias e tecnologias aplicadas à EAD; ênfase 2: gestão ambiental e sustentabilidade). Devido 


\section{CRIAR EDUCAÇÃO}

Revista do Programa de Pós-Graduação em Educação - UNESC

\section{unesc PPGE}

Criar Educação, Criciúma, v. 9, n²2, Edição Especial 2020.- PPGE - UNESC - ISSN 2317-2452

aos decretos de suspensão das atividades presenciais, esses cursos também foram interrompidos de 17 de março a 3 de maio de 2020, retomando todas as atividades a distância, conforme deliberações institucionais. As condições para continuidade dos cursos haviam sido alteradas devido ao isolamento social, e era necessário avaliar sua continuidade na tentativa de evitar a evasão e exclusão de acadêmicos(as) sem equipamento e acesso à internet, por exemplo.

Por isso, o ciclo de palestras online foi proposto ainda quando as atividades de ensino estavam suspensas e identificou-se uma queda de $25 \%$ de participação dos(as) acadêmicos(as), conforme as atividades de ensino foram sendo retomadas, justificadas pela dificuldade de conciliar a participação e o atendimento às demandas do trabalho, da família e/ou do curso. Dos 74 respondentes da avaliação final, 30\% relataram que assistiram a todas as palestras, $28 \%$ assistiram de 5 a 7 palestras, e $42 \%$ assistiram até 4 palestras.

O gráfico a seguir indicará o curso de graduação do CEAD/UDESC que os(as) 74 respondentes estavam vinculados(as).

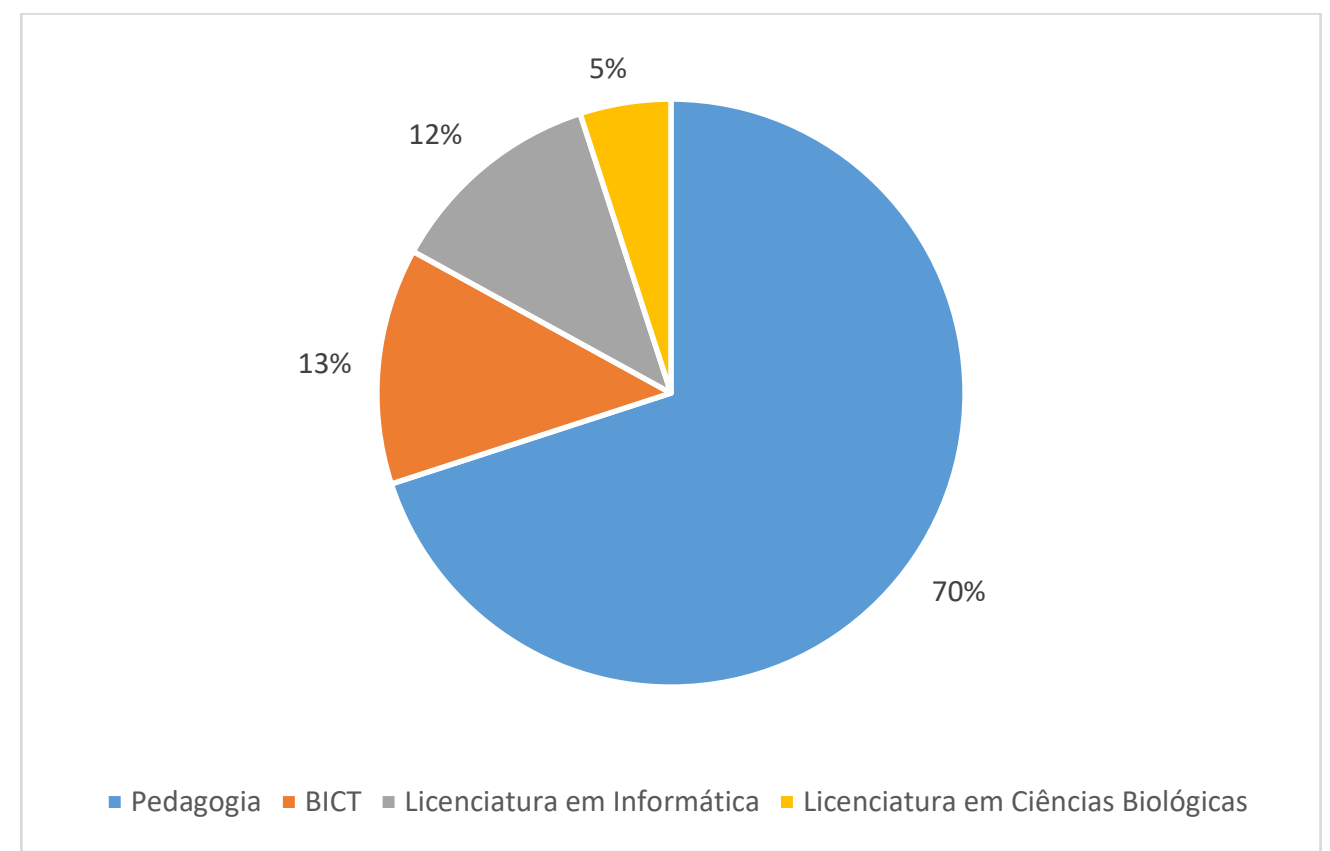

Gráfico 1 - Cursos de graduação dos(as) participantes

Fonte: elaborado pela autora/organizadora do ciclo de palestras online (2020). 


\section{CRIAR EDUCAÇÃO}

Revista do Programa de Pós-Graduação em Educação - UNESC

\section{Unesc PPGE}

Criar Educação, Criciúma, v. 9, n²2, Edição Especial 2020.- PPGE - UNESC - ISSN 2317-2452

Observa-se que $70 \%$ dos(as) acadêmicos(as) que participaram do ciclo de palestras online estavam vinculados(as) ao curso de Pedagogia, $13 \%$ ao curso de Bacharelado Interdisciplinar em Ciência e Tecnologia, 12\% ao curso de Licenciatura em Informática, e apenas 5\% ao curso de Licenciatura em Ciências Biológicas. Alguns(mas) participantes destacaram que os temas foram importantes para além do currículo e da formação inicial de professores, contribuindo para sua formação integral.

Foi de grande relevância para meu aprimoramento como pessoa [...]. (participante 1).

Temas importantíssimos, levando-nos a pensar nos como indivíduos sociais perante tudo isso. (participante 2).

Temas importantíssimos para o momento, e muito esclarecedores, como muitas coisas não fazem parte da nossa realidade diária muitas vezes acabamos nem percebendo a importância dos mesmos. (participante 3).

Contribuiu de forma muito significativa, oferecendo temáticas diferenciadas, mas todas pensadas em tempos de Pandemia e no isolamento social. (participante 4).

Apenas um(a) dos(as) participantes alegou que as temáticas tinham um vínculo maior com o curso de Pedagogia, não reconhecendo sua abrangência e possiblidade de discussão nos demais cursos.

Todas as palestras que eu participei estavam diretamente vinculadas a pedagogia, poderiam ter explorado outros temas vinculados a Tecnologia, Biologia e outros. (participante 5).

Dentre os(as) acadêmicos(as), observa-se maior participação do curso de Pedagogia, que totalizou $70 \%$ dos respondentes, e que também destacaram na avaliação do ciclo de palestras online a importância da atividade para sua formação acadêmica. Vale destacar que a maioria dos acadêmicos(as) ativos em 2020-1 estava vinculada ao curso de Pedagogia na modalidade a distância, que é oferecido pelo CEAD/UDESC há mais tempo e com maior regularidade das ofertas.

Temas muito bons, super bem escolhidos para o momento, palestrantes maravilhosos que vem nos acompanhando em toda nossa trajetória do curso de Pedagogia da UDESC. (participantes 6). 


\section{CRIAR EDUCAÇÃO}

Revista do Programa de Pós-Graduação em Educação - UNESC

\section{unesc PPGE}

Criar Educação, Criciúma, v. 9, n²2, Edição Especial 2020.- PPGE - UNESC - ISSN 2317-2452

Eu pude assistir apenas uma palestra mas que foi de grande valia para minhas decisões à respeito da pedagogia. (participante 7).

Em termos de faixa etária, a maioria dos(as) participantes tinha entre 31 e 50 anos, totalizando $63 \%$, conforme o Gráfico 2, a seguir, resultado coerente com o perfil dos(as) matriculados(as) em cursos do CEAD/UDESC ao longo dos últimos anos.

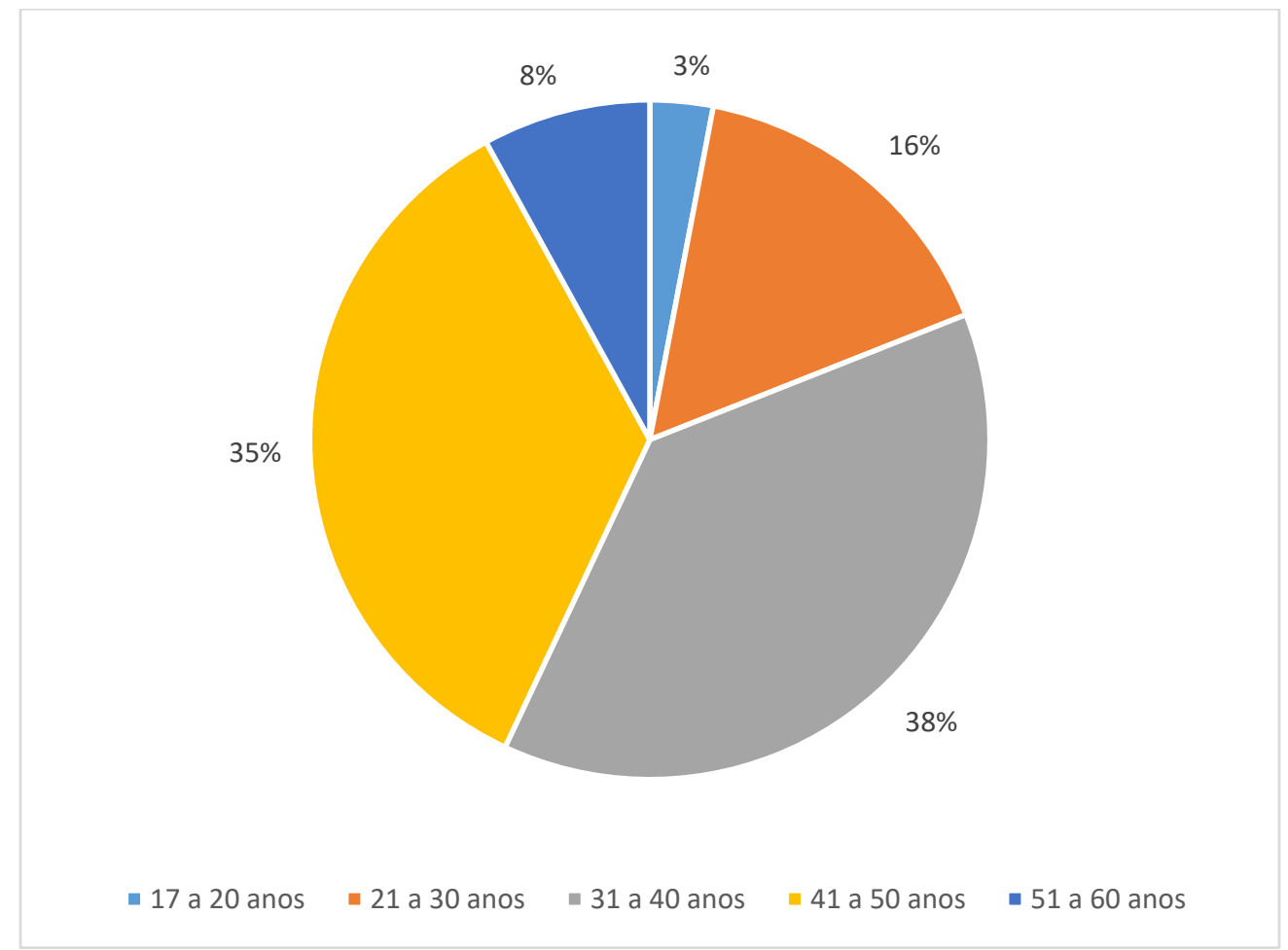

Gráfico 2 - Faixa etária dos(as) participantes

Fonte: elaborado pela autora/organizadora do ciclo de palestras online (2020).

Esses(as) acadêmicos(as) estavam vivenciando mudanças nas rotinas das suas famílias, pois passaram a assumir o ensino remoto dos filhos(as), muitos perderam o emprego, tiveram dificuldades emocionais provocadas pelo contexto da pandemia e não tinham equipamentos e recursos para dar continuidade ao curso. Esses foram os principais problemas identificados nas enquetes realizadas pelos(as) coordenadores(as) de curso e professores(as).

Mesmo com todos esses problemas, o número de participantes no ciclo de palestras online surpreendeu a organização da atividade. E foi importante saber se a 


\section{CRIAR EDUCAÇÃO}

Revista do Programa de Pós-Graduação em Educação - UNESC

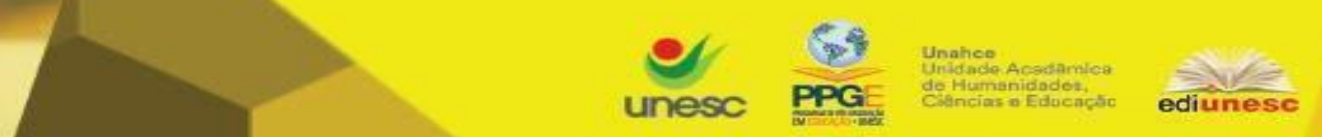

Criar Educação, Criciúma, v. 9, ํㅡ, Edição Especial 2020.- PPGE - UNESC - ISSN 2317-2452

atividade atendeu às expectativas dos(as) participantes. O Gráfico 3, a seguir, apresenta que $97 \%$ manifestaram que suas expectativas foram atendidas.

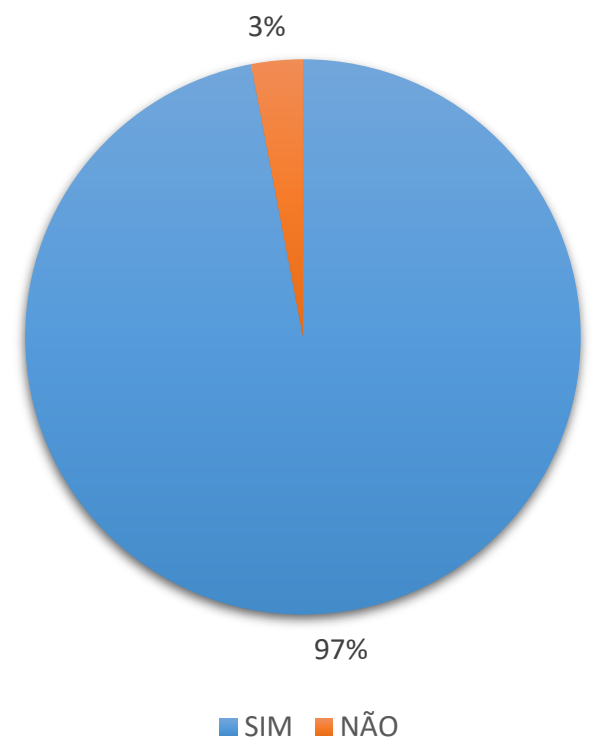

Gráfico 3 - Atendimento das expectativas dos(as) participantes Fonte: elaborado pela autora/organizadora do ciclo de palestras online (2020).

Alguns comentários apresentados a seguir justificam os motivos de os participantes considerarem que as expectativas foram atingidas:

Tanto a proposta em si quanto as palestras que consegui participar estavam excelentes! (participante 8).

Atendeu minhas expectativas e com certeza contribuiu muito para minha formação acadêmica. (participante 9).

Assuntos muito pertinentes com pessoas qualificadas para esclarecer dúvidas e trazer contribuições importantes. (participante 10).

Eu fiquei muito satisfeita com todas as palestras que assisti ao vivo e com as gravações que pude ver posteriormente. Tanto os conteúdos quanto a linguagem utilizada para a comunicação eram de ótima qualidade e acessíveis, acredito que contribuiu tanto para acadêmicos quanto para comunidade em geral. (participante 11). 


\section{CRIAR EDUCAÇÃO}

Revista do Programa de Pós-Graduação em Educação - UNESC

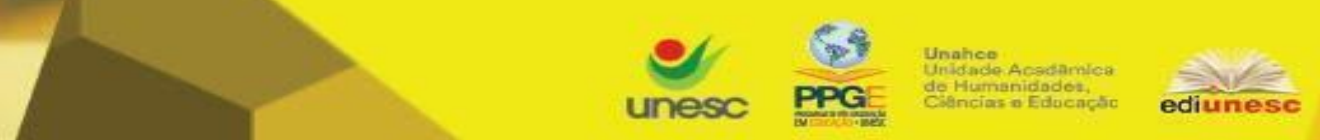

Criar Educação, Criciúma, v. 9, no2, Edição Especial 2020.- PPGE - UNESC - ISSN 2317-2452

$\mathrm{Na}$ avaliação, também solicitou-se para os(as) participantes registrarem uma nota ao ciclo de palestras online, no intuito de ter uma noção quantitativa dos objetivos atingidos, conforme o Gráfico 4 retrata.

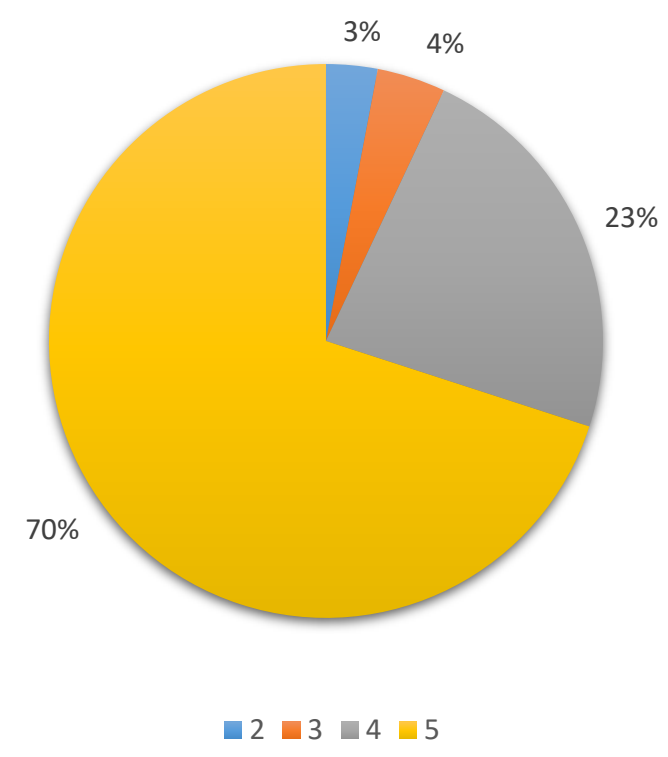

Gráfico 4 - Nota atribuída pelos(as) participantes ao ciclo de palestras online Fonte: elaborado pela autora/organizadora do ciclo de palestras online (2020).

Nenhum participante atribuiu nota 0 ou 1 para o ciclo de palestras. De uma escala de 0 a 5, sendo 5 a nota mais alta, 70\% dos participantes atribuíram a nota máxima, registrando os seguintes comentários:

Ótimo para refletir nesse momento inédito de isolamento e nos trouxe otimismo que podemos melhorar. (participante 12).

Todas as palestras do ciclo foram muito interessantes e trouxeram temas muito atuais para nossa reflexão em tempos de pandemia. As palestras me permitiram ter um olhar mais sensível e crítico para a realidade que estamos vivenciando. (participante 13).

As palestras foram ótimas, algumas além das expectativas, porém em função da conexão da internet em algumas ficou difícil de entender completamente as falas. (participante 14). 


\section{CRIAR EDUCAÇÃO}

Revista do Programa de Pós-Graduação em Educação - UNESC

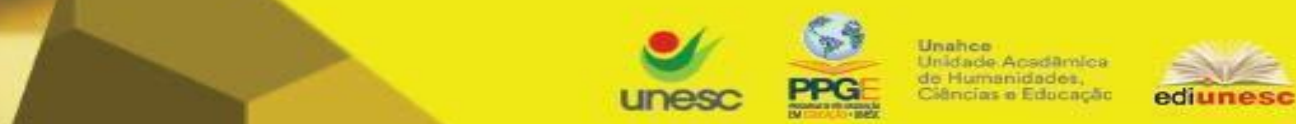

Criar Educação, Criciúma, v. 9, n²2, Edição Especial 2020.- PPGE - UNESC - ISSN 2317-2452

Sobre essa última afirmação do(a) participante 14, que ressaltou problemas de conexão à internet, o Gráfico 5, a seguir, mostra as maiores dificuldades dos(as) acadêmicos(as).

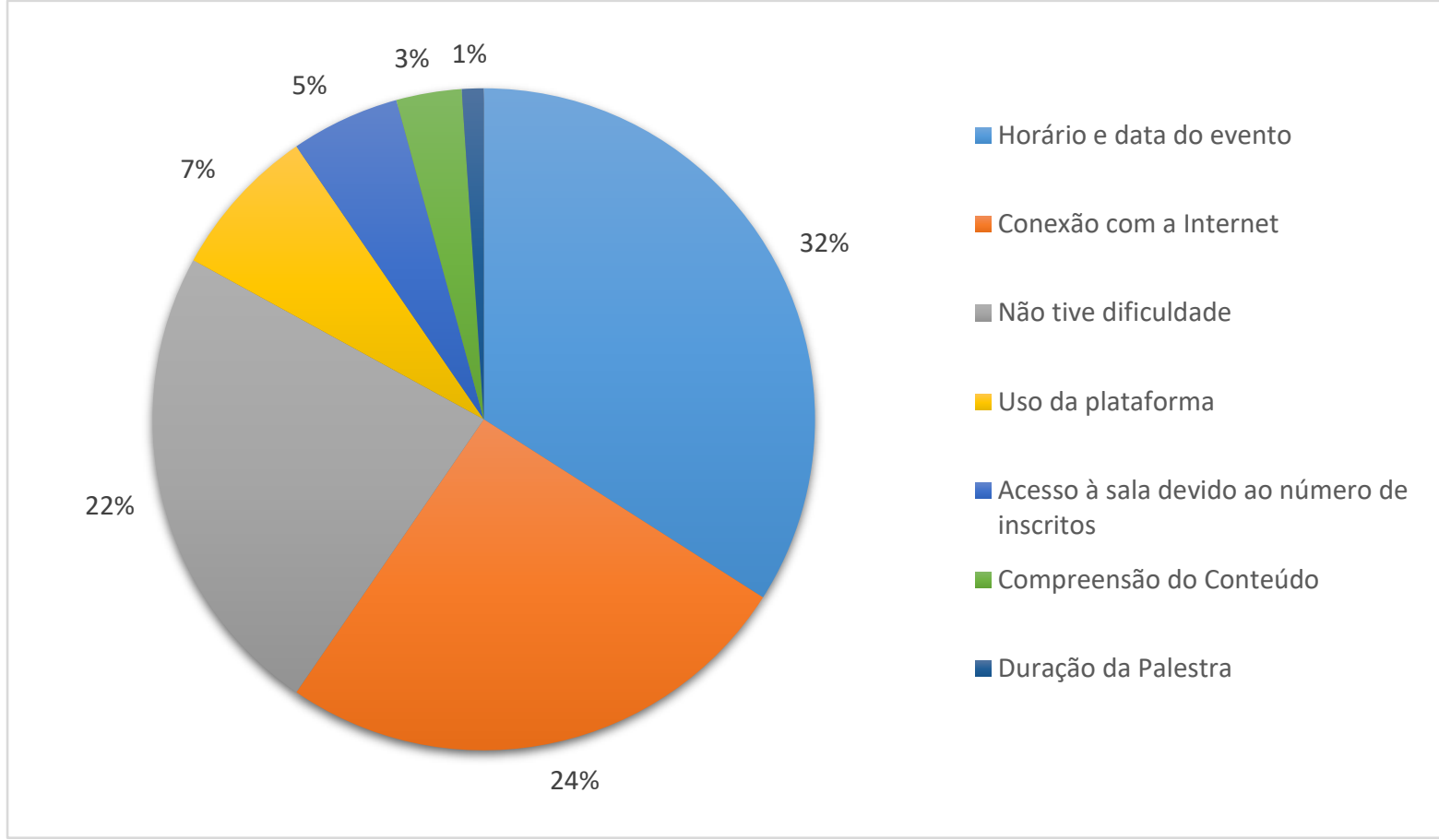

Gráfico 5 - Dificuldades dos(as) participantes

Fonte: elaborado pela autora/organizadora do ciclo de palestras online (2020).

A maior dificuldade relatada pelos(as) acadêmicos(as) para participar do ciclo de palestras online refere-se ao horário da atividade, que foi concentrado no período da tarde, considerando-se que se tratava de uma atividade complementar e era necessário atender à disponibilidade de todos(as) envolvidos(as). Além disso, em um contexto de trabalho remoto, a conexão com a internet foi responsável por $24 \%$ das dificuldades relatadas, seja por falta de estrutura na residência ou por problemas de instabilidade das redes. Também se destaca que $22 \%$ afirmaram não ter dificuldade, e outros problemas foram relatados em menor quantidade: uso da plataforma (7\%), acesso à sala devido ao número limitado de até 75 usuários (5\%), compreensão do conteúdo (3\%), e duração da palestra (1\%). 


\section{CRIAR EDUCAÇÃO}

Revista do Programa de Pós-Graduação em Educação - UNESC

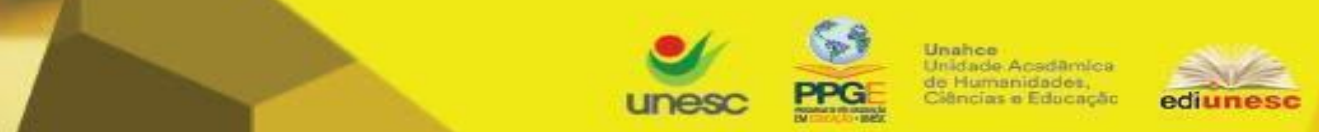

Criar Educação, Criciúma, v. 9, n²2, Edição Especial 2020.- PPGE - UNESC - ISSN 2317-2452

Apesar de reconhecer esses limites, conforme já mencionado, as palestras tinham como objetivo o acolhimento dos(as) acadêmicos(as), com o propósito de ampliar as discussões sobre o contexto da pandemia e contribuir para a permanência nos cursos de graduação do CEAD durante a suspensão das aulas. O Gráfico 6, a seguir, apresenta os resultados dessa questão.

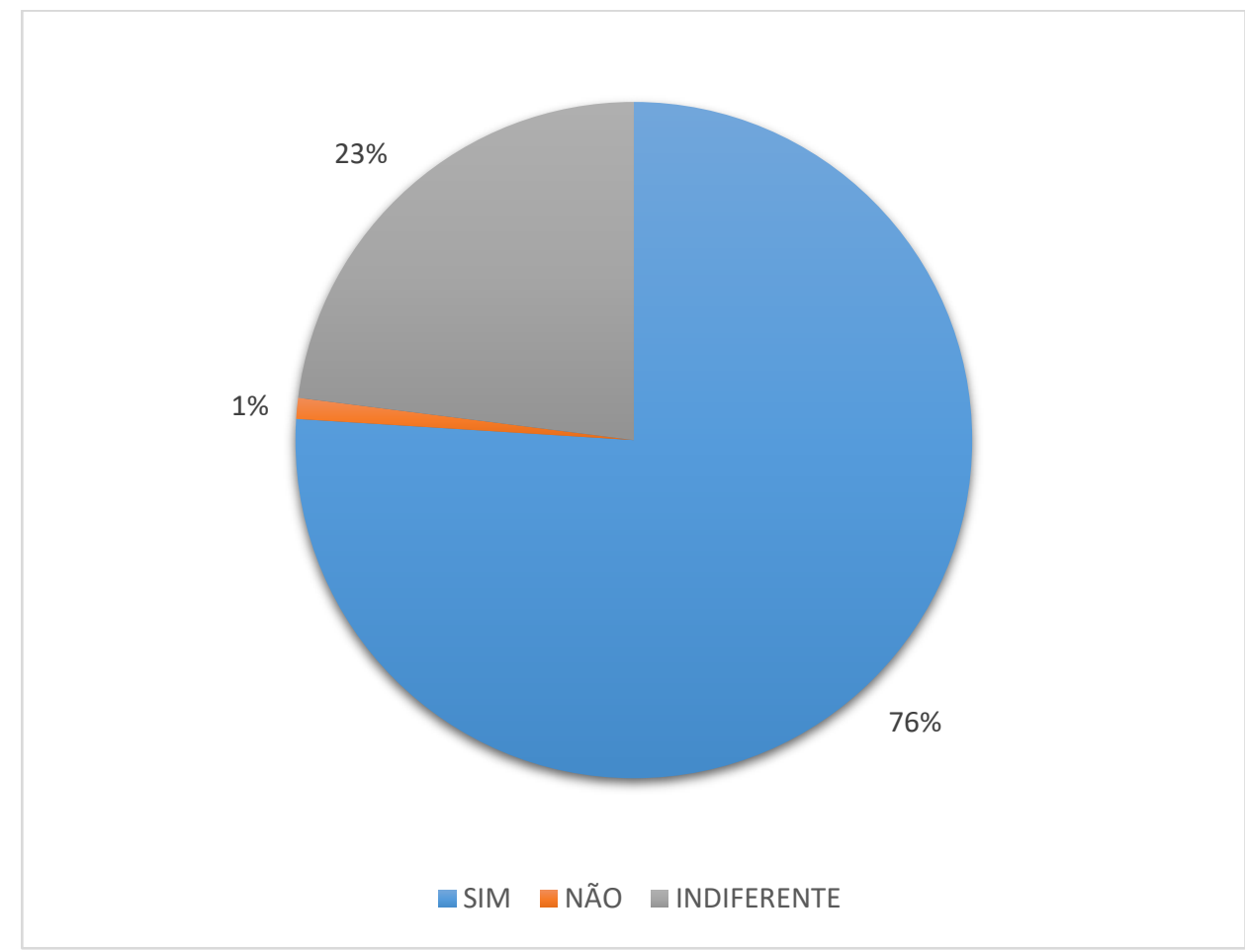

Gráfico 6 - Contribuição para permanência no curso de graduação

Fonte: elaborado pela autora/organizadora do ciclo de palestras online (2020).

Do total de respondentes, observa-se que $76 \%$ dos(as) acadêmicos(as) afirmaram que a participação no ciclo de palestras online, oferecido no período de suspensão do calendário acadêmico, contribuiu para sua permanência no curso. Para $17 \%$, a participação não impactou nessa escolha, e apenas $1 \%$ assinalou que não contribuiu. Na avaliação, alguns(mas) participantes registraram sua percepção:

A palestra que assisti foi muito incentivadora para eu continuar no curso, mesmo com problemas devido à pandemia, me fez repensar no futuro e no quanto a educação é importante na era digital. O quanto ainda precisamos nos adequar ao período tecnológico e às transformações. (participante 15). 


\section{CRIAR EDUCAÇÃO}

Revista do Programa de Pós-Graduação em Educação - UNESC

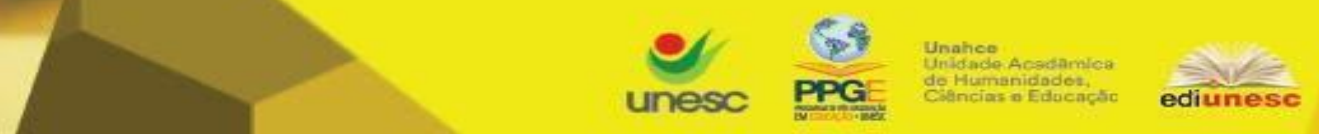

Criar Educação, Criciúma, v. 9, n²2, Edição Especial 2020.- PPGE - UNESC - ISSN 2317-2452

Achei muito relevante nesse momento tão difícil que estamos passando, fazendo com que as pessoas possam entender que todos estão tendo algumas dificuldades, tanto os professores, como os alunos, pois ninguém estava preparado para passar por este momento. (participante 16).

Para finalizar, apresenta-se a avaliação dos(as) acadêmicos(as) sobre as temáticas escolhidas para o ciclo de palestras online, sendo que, em termos de relevância, $69 \%$ consideraram muito relevante, $28 \%$ consideraram relevante, e apenas $3 \%$ dos participantes afirmaram ter pouca relevância.

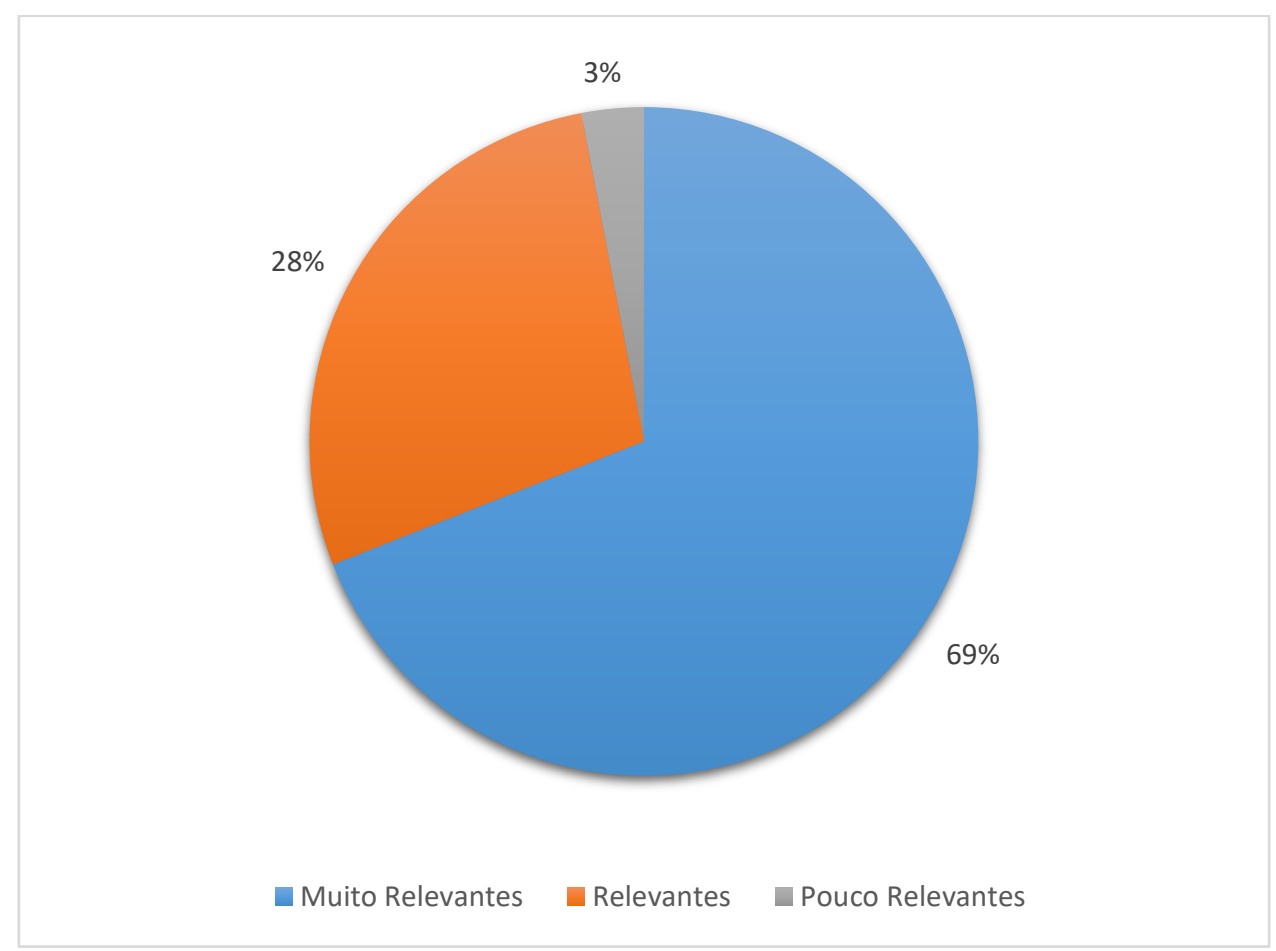

Gráfico 7 - Relevância das temáticas

Fonte: elaborado pela autora/organizadora do ciclo de palestras online (2020).

Todos(as) os(as) respondentes registraram que gostariam que houvesse continuidade desse ciclo de palestras online e os temas sugeridos em maior quantidade foram: educação ambiental e sustentabilidade, tecnologias, educação inclusiva e mudanças na educação pós-pandemia. 
Dessa forma, fica o desafio para o Grupo de Pesquisa Nexos: Teoria Crítica e Educação - Sul avaliar o impacto dessa atividade, que envolveu ensino, pesquisa e extensão, e fazer outras proposições a partir das sugestões registradas.

\section{0 ciclo de palestras online e sua contribuição para a (auto)reflexão crítica}

No dia 11 de março de 2020, a Organização Mundial da Saúde decretou pandemia pelo novo coronavírus. As instituições escolares foram as primeiras a ter as atividades suspensas e, a partir da publicação da Portaria ํㅡ 343, de 17 de março de 2020, que autorizou a substituição das disciplinas presenciais, em andamento, por aulas que utilizem meios e tecnologias de informação e comunicação (BRASIL, 2020a), observou-se a improvisada implantação de atividades pedagógicas não presenciais por meio da invenção do ensino remoto. Importante destacar que, pela Lei de Diretrizes e Bases da Educação Brasileira, № 9.394, de 20 de dezembro de 1996, apenas a educação a distância é prevista enquanto modalidade de ensino (BRASIL, 1996).

Com o crescimento exorbitante dos casos confirmados da Covid-19, trazendo tantas incertezas para as pessoas, no campo da educação, a discussão sobre o calendário acadêmico tornou-se a prioridade, envolvendo antecipação das férias e/ou recesso, bem como convocações para a formação do docente online, com o objetivo de possibilitar uma retomada imediata das atividades via processos de virtualização do ensino. Um problema de gestão, que ignorava os aspectos pedagógicos e deixava em segundo plano o acolhimento e a solidariedade que poderiam ser os pontos fundamentais dos planejamentos institucionais nesse contexto.

A suspensão das atividades de ensino também atingiu os cursos de EAD não apenas no CEAD/UDESC. Era preciso avaliar o impacto do fechamento dos polos de apoio presencial e mapear as necessidades que cada um(a) dos(as) acadêmicos(as) para dar continuidade aos cursos. Algo que, em um primeiro momento, foi visto como contraditório, já que se trata de uma modalidade que já utilizava o aparato tecnológico para seu desenvolvimento. Os cursos instrucionais a distância, massivos, que têm momentos limitados de mediação e intervenção docente, que são mercantilizados 
independentemente da realidade dos(as) cursistas, poderia não ter entraves para sua continuidade. Aqueles que fogem dessa lógica precisavam analisar a continuidade de forma responsável considerando-se a permanência de todas as pessoas.

Algumas redes, instituições e grupos chamaram a atenção para a necessidade dessa perspectiva, tal como fizeram a Rede Escola Pública e Universidade (REPU) e o Grupo Escola Pública e Democrática (GEPUD) em publicação de 8 de abril 2020:

Os eventuais encontros virtuais entre estudantes e professores não devem ser espaços de transmissão de conteúdos pura e simples, mas de promoção de diálogos e de fortalecimento de laços de solidariedade, sendo este o melhor apoio que se pode dar à formação e ao desenvolvimento das crianças e adolescentes em um momento tão difícil. Tais encontros, além disso, devem reforçar a dimensão pública da escola e o seu papel de formação para a cidadania, valorizando todos os profissionais da educação e estimulando-os a atuarem, junto às suas escolas e redes de ensino, na defesa dos direitos de crianças e adolescentes e do direito à educação (REDUC; GEPUD, 2020).

Observa-se que muitas redes tomaram medidas apressadas, atropelaram um processo de discussão com a comunidade escolar, esvaziando o princípio da gestão democrática na ânsia de migrar do presencial para o online. O diálogo, o fortalecimento de laços de solidariedade, a dimensão pública e o papel das instituições escolares na formação da cidadania não tiveram eco.

Nesse sentido, torna-se ainda mais atual a discussão proposta por Adorno (2003), no texto Educação - para quê?, pois que contribui para se pensar o impacto dessas ausências. Ao expor sua concepção de educação, o autor frankfurtiano afirma:

Evidentemente não a assim chamada modelagem de pessoas, porque não
temos o direito de modelar pessoas a partir do seu exterior: mas também não
a mera transmissão de conhecimentos, cuja característica de coisa morta já
foi mais do que destacada, mas a produção de uma consciência verdadeira.
Isto seria inclusive da maior importância política; sua ideia, se é permitido
dizer assim, é uma exigência política. (ADORNO, 2003, p. 141, grifo do autor).

A produção de uma consciência verdadeira, enquanto exigência política, diluise ainda mais nesse contexto de pandemia e é silenciada em diversas dimensões. A formação da equipe docente, por exemplo, acabou priorizando os aspectos técnicos em detrimento das discussões pedagógicas, mantendo-se a característica de "coisa morta", mencionada por Adorno (2003), justificada pelo consenso de que os(as) 
professores(as) não se sentiam preparados(as) para usar as tecnologias. A formação tornou-se instrumental e aligeirada, deixando de abordar questões fundamentais, como, por exemplo, o atendimento aos(às) estudantes com deficiência, às mudanças sociais provocadas pela Covid-19, e aos limites e potencialidades das tecnologias digitais de rede. Além disso, a exclusão de grande parte dos(as) estudantes sem estrutura, tal como constatado pela UNESCO (2020), não tem tido a atenção necessária.

Desse modo, alguns questionamentos, que são considerados primordiais, acabaram sendo silenciados nessa retomada do semestre letivo: quais conteúdos aproximariam educadores(as), extensionistas e pesquisadores(as) da comunidade escolar? Como manter vínculo e usar as TICs para construir uma consciência comunitária, que resgate a ideia de uma comunidade escolar? Qual projeto pedagógico de curso se quer durante e pós-pandemia? Como garantir acesso aos processos de ensino-aprendizagem para todas as pessoas? Como fortalecer laços de solidariedade e acolhimento diante da pandemia da Covid-19?

Nesse contexto, era preciso ampliar as concepções de currículo que se limitam a seguir as grades de disciplinas e suas ementas aprovadas em âmbito institucional. Era necessário fazer a reflexão, de forma crítica, da situação social, econômica, política, ética e cultural que a pandemia deixou ainda mais desmascarada. $\mathrm{O}$ ano letivo não poderia simplesmente retomar de onde parou. Outras temáticas, tais como as que foram propostas no ciclo de palestras online, poderiam ser iniciativas de atender a esses propósitos, com os limites que eram previstos e foram confirmados nas avaliações, tal como a disponibilidade de horário e falta de estrutura dos(as) participantes. Apenas 22\% apontaram que não tiveram problemas.

Mesmo assim, pode-se reconhecer que essa iniciativa contribuiu para promover diálogos, interações e acolhimento dos(as) acadêmicos(as), tal como observado nos relatos das avaliações, que destacaram, principalmente, o quanto o ciclo de palestras online ajudou a compreender o contexto da pandemia, a entender que as dificuldades não eram apenas individuais, a reconhecer que não se estava preparados(/as) para 
enfrentar a Covid - 19, a permanecer no curso, a repensar o futuro, a ressignificar a importância da educação, a se aproximar dos(as) professores(as).

Por isso, reafirma-se a importância de que as decisões sobre o retorno ou não das atividades de ensino para cumprir os fluxos institucionais e o cumprimento de uma matriz curricular consolidada não poderiam inibir a discussão de temáticas que se faziam urgentes e necessárias no contexto da pandemia. E os(as) participantes também apontaram a contribuição do ciclo de palestras online nesse sentido, afirmando que os temas abordados foram importantes para refletir sobre um momento inédito, permitindo um olhar mais sensível e crítico, colocando-os(as) para pensar como indivíduos sociais. Conforme mencionado no item anterior, 69\% consideraram os temas muito relevantes, e $28 \%$ relevantes. Apenas $3 \%$ consideraram pouco relevante.

É inegável que a situação da pandemia da Covid-19 provoca um enorme desafio educativo. Destaca-se que o ciclo de palestras online foi apenas uma tentativa de propor ações para a formação e o desenvolvimento da (auto)reflexão crítica da comunidade acadêmica.

Vive-se em um mundo administrado que, tal como denunciam os estudos fundamentados na Teoria Crítica da Sociedade, estimula a substituição da experiência formativa pela semiformação socializada, da civilização pela reincidência da barbárie, da educação emancipatória pela educação danificada. Porém, essa mesma sociedade que se apresenta coesa ainda deixa brechas para vislumbrar algumas possibilidades. Segundo Adorno (2013), uma educação que recupere sua dimensão política e desenvolva a autorreflexão crítica, a autonomia, a reeducação dos sentidos e a relação histórica dos conteúdos culturais, ao invés da adaptação e do conformismo, poderia contribuir nesse processo. Por isso, a Teoria Crítica da Sociedade insiste na necessidade da crítica negativa e na tentativa de se aproximar das contradições da sociedade administrada e do que aparece como camuflado. Adorno (2010, p. 39) enfatiza que "[...] a única possibilidade de sobrevivência que resta à cultura é a autorreflexão crítica sobre a semiformação, em que necessariamente se converteu." 


\section{Considerações finais}

No texto Educação danificada, Ramos-de-Oliveira (1997, p.32) destaca no aforismo "viver e viver", recuperando os escritos de Walter Benjamin, a relação entre erlebnis versus erfahrung: "[...] eis aí delineadas a vida como objeto e a vida como sujeito, a vida como reflexo e a vida como reflexão, a vida que se dissipa e a vida que se vive de fato, em extensão e profundidade." Todas as pessoas estão presenciando, sofrendo e vivendo os impactos provocados pela pandemia e a implantação de uma educação danificada, de forma remota, sob os discursos de cunho mercadológico da urgência de voltar à normalidade, ao custo de colocar pessoas em risco, de fragmentar ainda mais o processo de ensino-aprendizagem, de excluir quem se encontra em situação de vulnerabilidade social, de se afastar das possibilidades de viver e desenvolver a autorreflexão crítica.

Dessa forma, pode-se pensar: o que tem possibilitado essa educação remota em tempos de pandemia provocada pelo novo coronavírus? A erlebnis que apenas acrescenta passagem do tempo? Ou a erfahrung que modifica, altera, ensina, relaciona e possibilita a rememorização de vínculos coletivos, que estruturam a individualidade? (RAMOS-DE-OLIVEIRA, 1997).

São 9.641 .472 casos confirmados de pessoas com Covid-19 em âmbito mundial (dados de 26 de junho de 2020). E, mesmo assim, são as exigências de um capitalismo perverso que continuam a ser os determinantes dos rumos das políticas públicas, acelerando o encolhimento das pautas sociais. A denúncia do mito da razão de Adorno e Horkheimer (1985), infelizmente, está atualizada nesse contexto. O Brasil mantém sua agenda conservadora e de aproximação com o fascismo, na qual impera o discurso de ódio, a propagação do anticientificismo e do antiambientalismo, com ações de racismo e machismo.

O ciclo de palestras online se efetivou nesse contexto de incertezas, de resistências e de angústia. De isolamento social, de trabalho remoto e de suspensão de atividades de ensino. Mesmo assim, o Grupo de Pesquisas Nexos: Teoria Crítica 


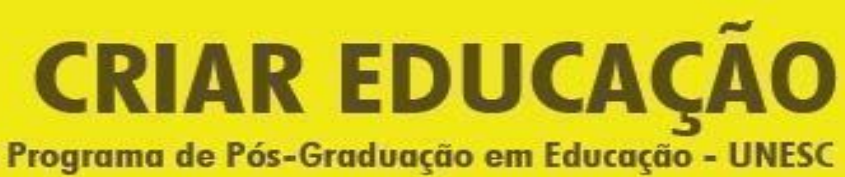

Revista do Programa de Pós-Graduação em Educação - UNESC

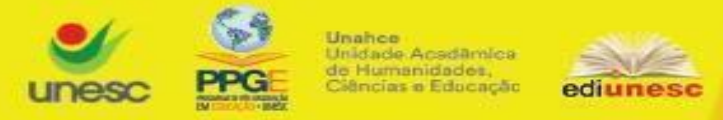

Criar Educação, Criciúma, v. 9, №2, Edição Especial 2020.- PPGE - UNESC - ISSN 2317-2452

e Pesquisa Interdisciplinar - Sul reconheceu que era necessário ter momentos para debater esse contexto e, ao mesmo tempo, acolher a comunidade acadêmica. Talvez, o grupo tivesse a esperança de que se pudesse cavar um espaço para tentativas de recuperar a formação crítica, demonstrando que um calendário acadêmico pode ser mais do que uma resolução ou normativa institucional.

\section{REFERÊNCIAS}

ADORNO, Theodor. W. Teoria da semiformação. Tradução: Newton Ramos-deOliveira. In: PUCCI, Bruno; ZUIN, Antonio A. S.; LASTÓRIA, Luiz A. C. N. (org.). Teoria Crítica e Inconformismo: novas perspectivas de pesquisa. Campinas-SP: Autores Associados, 2010.

ADORNO, Theodor W. Educação - para quê? In: Educação e Emancipação. $3^{\text {a }}$ Edição. Rio de Janeiro: Paz e Terra, 2003.

ADORNO, Theodor W. HORKHEIMER, Max. Dialética do esclarecimento: fragmentos filosóficos. Tradução: Guido Antonio de Almeida. Rio de Janeiro: Jorge Zahar, 1985.

BRASIL. Ministério da Educação. Conselho Nacional de Educação. Portaria no 343, de 17 de março de 2020. Dispõe sobre a substituição das aulas presenciais por aulas em meios digitais enquanto durar a situação de pandemia do novo coronavírus - COVID-19. 2020a. Disponível em: <http://www.in.gov.br/en/web/dou/-/portaria-n343-de-17-de-marco-de-2020-248564376>. Acesso em: 29 jun. 2020.

BRASIL. Ministério da Educação. Conselho Nacional de Educação. Parecer CNE no 5, de 28 de abril de 2020. Dispõe sobre a reorganização do calendário escolar e sobre a possibilidade de cômputo de atividades pedagógicas não presenciais para fins de cumprimento da carga horária mínima anual, em razão da pandemia da Covid-19. 2020b. Disponível em:

$<$ http://portal.mec.gov.br/index.php?option=com_docman\&view=download\&alias $=14$ 5011-pcp005-20\&category_slug=marco-2020-pdf\&ltemid=30192>. Acesso em: 18 jun. 2020.

BRASIL. Lei no 9.394, de 20 de dezembro de 1996. LDB - Lei de Diretrizes e Bases da Educação Brasileira. Disponível em:

<http://www.planalto.gov.br/ccivil_03/leis//9394.htm>. Acesso em: 19 jun. 2020.

RAMOS-DE-OLIVEIRA. Reflexões sobre a Educação Danificada. In: PUCCI, Bruno et. Al (orgs). A Educação Danificada: contribuições à Teoria Crítica da Educação. $2^{\mathrm{a}}$ ed. São Paulo: Vozes, 1997.

REPU; GEPUD. A escola pública e as ações do governo de São Paulo frente à pandemia: questões em aberto. Publicado em: 8 abr. 2020. Disponível em: <https://esquerdaonline.com.br/2020/04/08/a-escola-publica-e-as-acoes-do-governo- 


\section{CRIAR EDUCAÇÃO}

Revista do Programa de Pós-Graduação em Educação - UNESC

\section{$x-2=$ ediunesc}

Criar Educação, Criciúma, v. 9, n²2, Edição Especial 2020.- PPGE - UNESC - ISSN 2317-2452

doria-sao-paulo-frente-a-pandemia-de-covid-19-questoes-em-aberto/\#notas>. Acesso em: 10 jun. 2020.

THE DALI Museum. Geopoliticus Criança assistindo o nascimento do novo homem. São Petersburgo, FL 2017. Disponível em:

$<$ https://archive.thedali.org/mwebcgi/mweb.exe?request=record;id=126;type=101 >. Acesso em: 28 jun. 2020.

UDESC. CEAD. Ciclo de palestras. Programação. 2020. Disponível em: <https://www.udesc.br/cead/cppandemia>. Acesso em: 19 jun. 2020.

UDESC. Resolução 026, de 13 de novembro de 2012 - CONSEPE. Regulamenta as atividades complementares nos cursos de graduação da UDESC. Disponível em: $<$ https://www.udesc.br/cct/portalacademico/atividades_complementares $>$. Acesso em: 20 jun. 2020.

UNESCO. Relatório mundial de acompanhamento sobre a educação 2020 "Inclusão e educação: todos, sem excepção". Disponível em:

<https://www.cvunesco.org/educacao/educacao-para-todos/11-destaques/407-

relatorio-mundial-de-acompanhamento-sobre-a-educacao-2020-inclusao-e-

educacao-todos-sem-excepcao-lancamento-virtual>. Acesso em: 25 jun. 2020. 


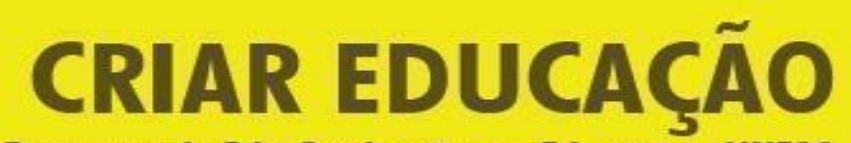

Revista do Programa de Pós-Graduação em Educação - UNESC

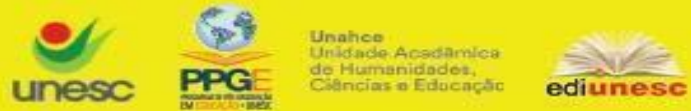

Criar Educação, Criciúma, v. 9, n²2, Edição Especial 2020.- PPGE - UNESC - ISSN 2317-2452

Recebido abril de 2020

Aprovado junho de 2020 